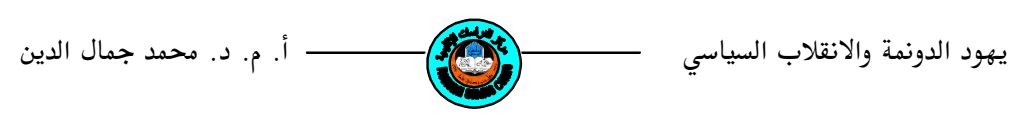

$$
\text { يهود الدونمة والانقلاب السياسي العثماني } 1908
$$

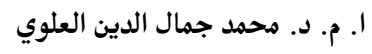

كلية العلوم السياسية / جامعة الموصل مجدم الدين العلوي

\begin{abstract}
مستخلص البحث
في النصف الثاني من القرن السابع عشر، مرت الدولة العثمانية في ظروف تاريخية وسياسية كانـت الدانت

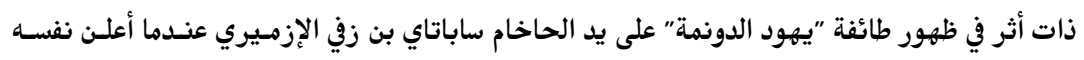
مسيحاً منتظراً. وهذه الطائفة اليهودية تتظاهر بالدين الإسلامي، في حين تمارس طقوساً دينية خاصة بها في الخفاء الخاء

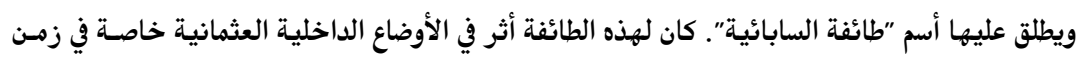

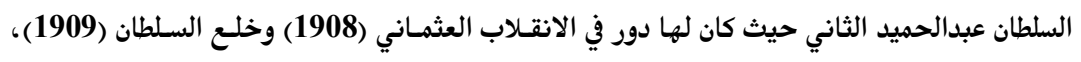

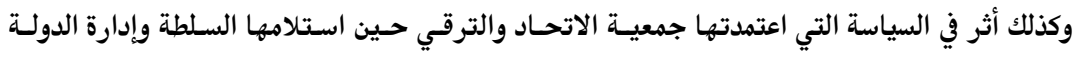

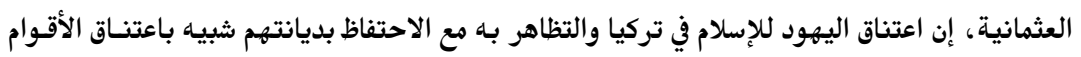
الأخرى للإسلام من أجل تحقيق أهداف عقيدتهم الأصلية.

مقدمة ظهرت طائفة الدونمة في تركيا خلال الحكم العثماني في النصف الثاني من القرن السابع

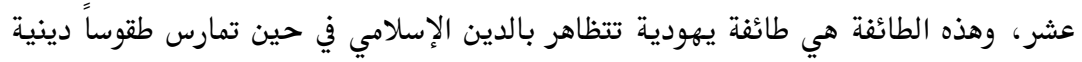

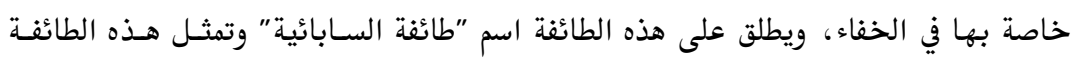
ظاهرة لاتخلو من الغرابة في التاريخ. فيطاه
\end{abstract}


كان لطائفة الدونمة اثر في الأوضاع الداخلية العثمانية خاصـة زهسن السـلطان عبدالحميسد

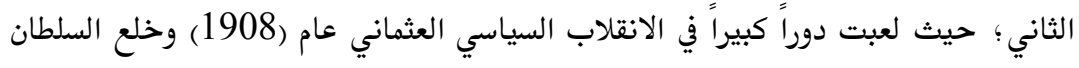

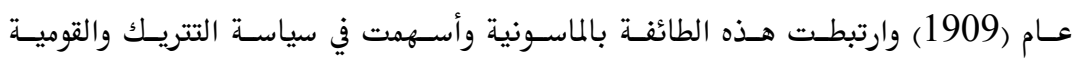
(الطورانية) والعلمانية، وتعاطفت مع الصهيونية وأهدافها.

$$
\text { أهمية البحث }
$$

تكمن أهمية البحث في الكشف عن دور يهـود الدونمـة في الانقـلاب السياسـي العثمـاني

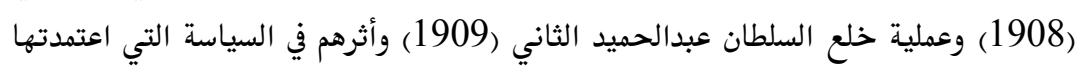
جماعة الاتحاد والترقي في إدارة الدولة.

\section{هيكلية البحث}

تضمن هذا البحث مبحثين تطرق المبحث الأول إلى ظاهرة طائفة الدونمة من حيث الأصل

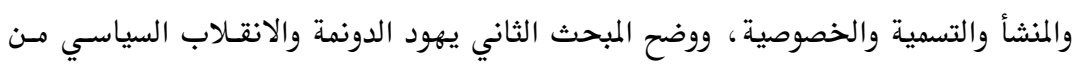

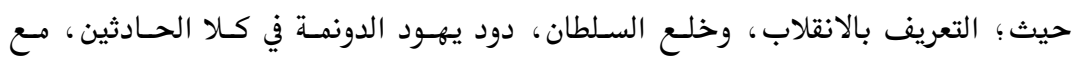

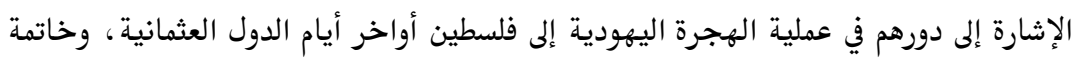

$$
\text { تضمنت أهم الاستنتاجات التي توصل إليها الباحث. }
$$

$$
\begin{aligned}
& \text { المبحث الأول : ظاهرة الدونمة } \\
& \text { أولاً: ظهور الطائفة الأول }
\end{aligned}
$$

هنـاك ظـروف وعوامـل تاريخيـة وسياسية ونفسية سـاعدت على ظهـور طائفـة يهـود

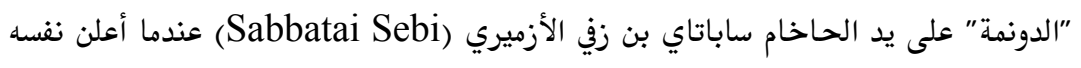

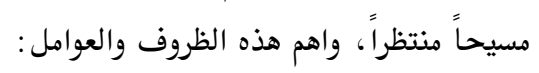

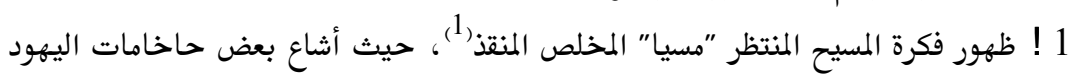

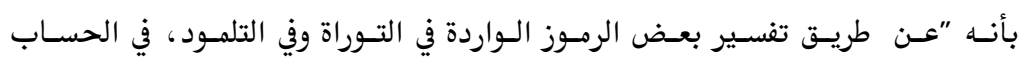

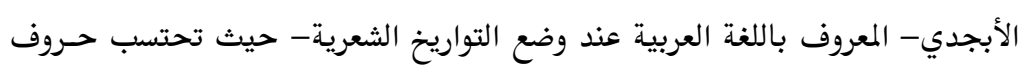




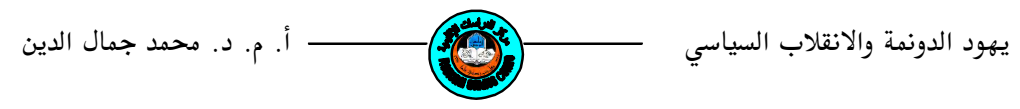

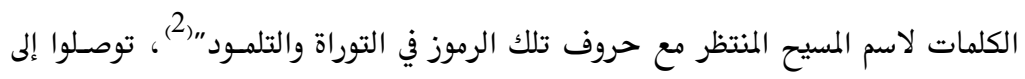

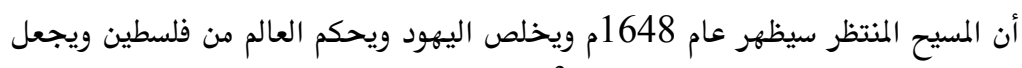
القدس عاصمة ومركزاً للدولة اليهودية" (3).

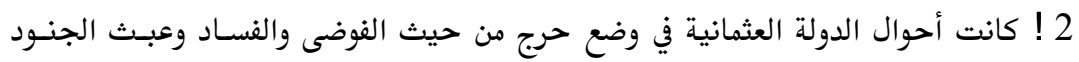

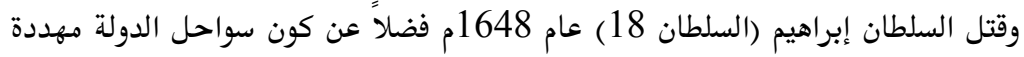
من قبل أساطيل البندقية.4. (3.). 3 ! في تلك الفترة كانت أوربا تعيش محاكم التفتيش، وكبــت الحريـات الدينيـة واضـطهاد

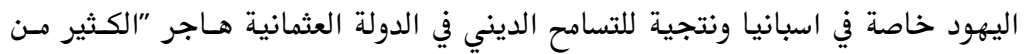
يهود اسبانيا والبرتغال إليها" (5.).

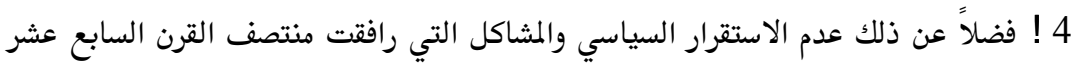

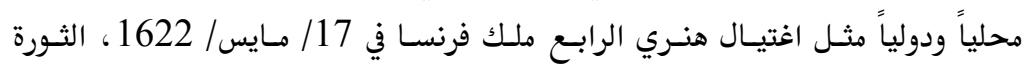

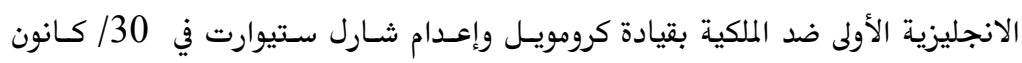

الثاني/ الانجليزية الاولى فد 1648 في تلك الفترة نشأ (ساباتاي) (7) في بيئة تلمودية متزمتة وقد استهواه تعلق اليهود بالمسيح

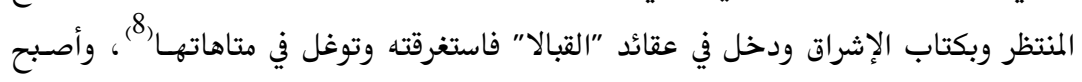

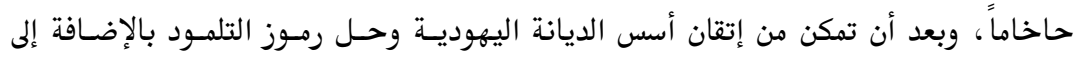

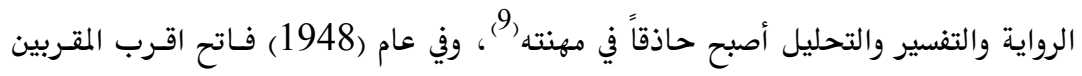

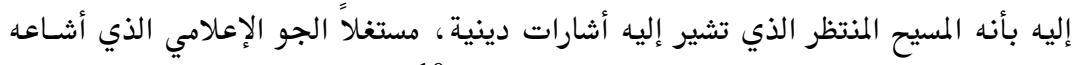
بعض حاخامات اليهود عن قرب ظهور المسيح المنتظر (10).

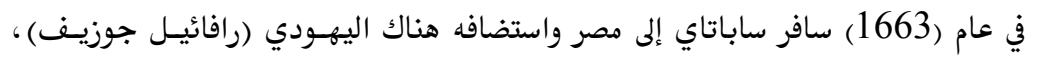

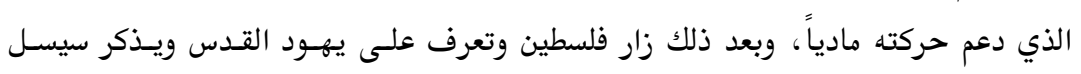

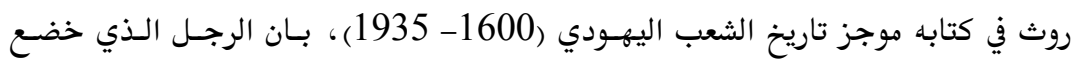

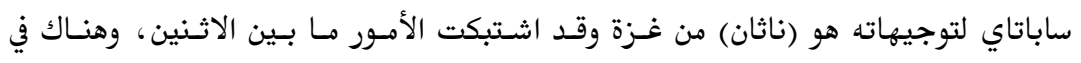

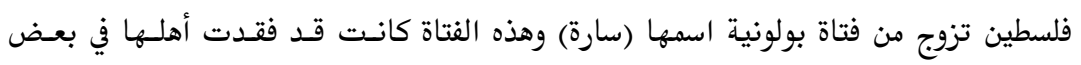


المذابح وأخذت إلى إحدى الأديرة ونصرت إلا أنها هربت وجاءت إلى فلسطين(11). ورافتته. سارة في طريق عودته إلى أزمير عام 1666 وأصبح هناك ذو شهرة ومكانة لدى الأدئ اليهود (12.).

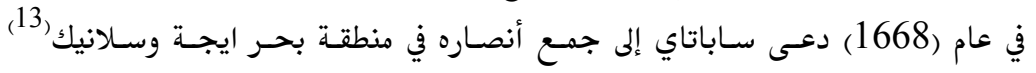

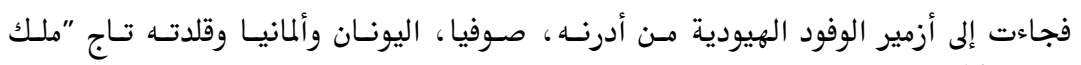

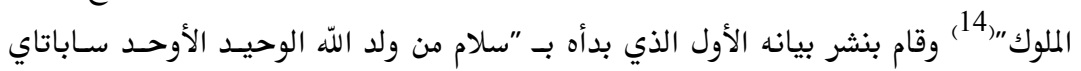

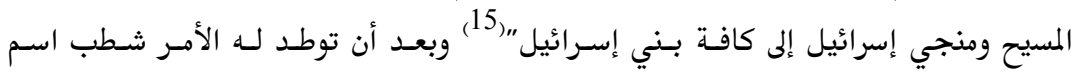

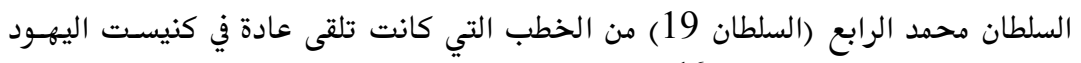
ووضع اسمه محل اسم السلطان(16) وأصبحت صلوات اليهود في الكنيست تفنتح بـ "ياملكنا-

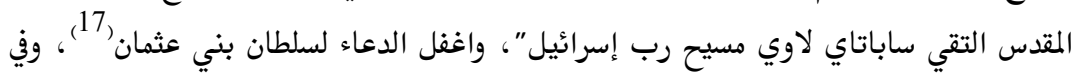

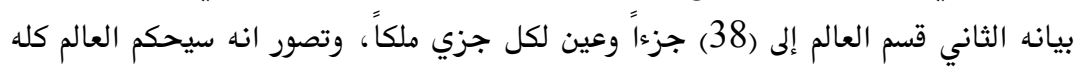

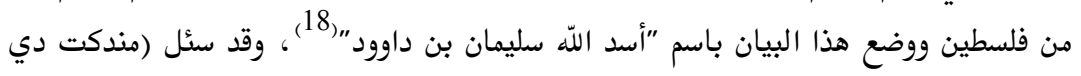

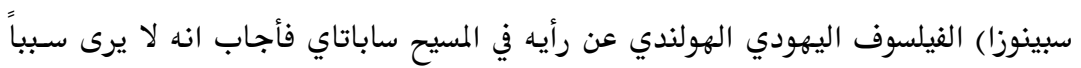
عقلياً يمنع امكانية إعادة الحكم الزمني إلى اليهود (19).

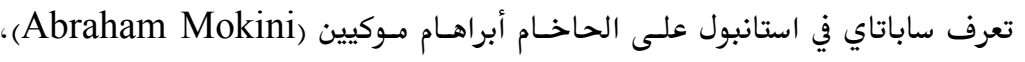

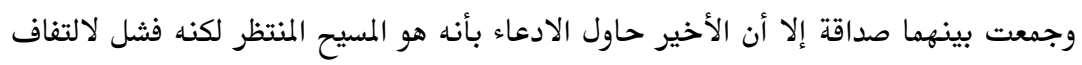

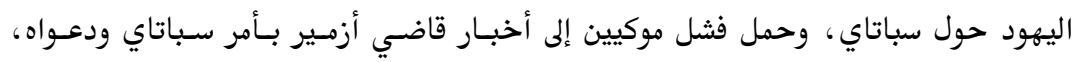

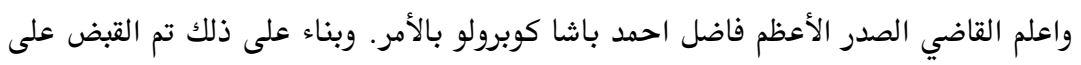

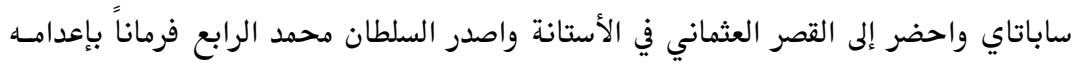

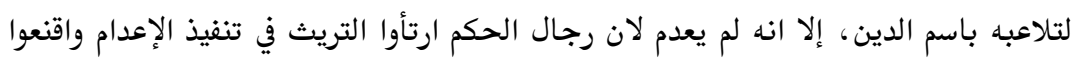

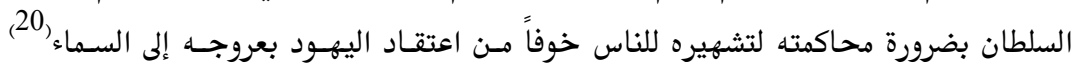

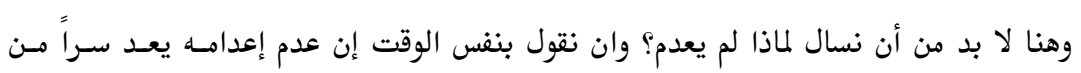

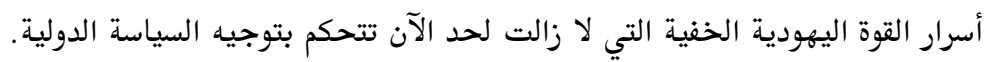

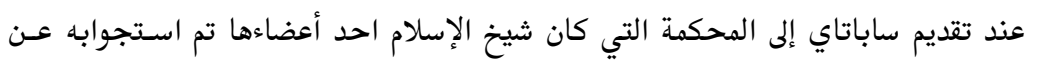

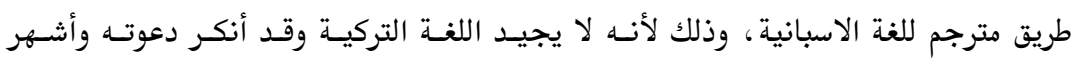


يهود الدونمة والانقلاب السياسي

إسلامه، ، وبعد ادعاءه انه أصبح مسلماً عرف باسم "محمد عزيز" وقد كان المترجم هو الضابط الطبيب مصطفى حياتي المسلم في الظاهر واليهودي في الخفاء وهو من اليهود الذين استجاروا

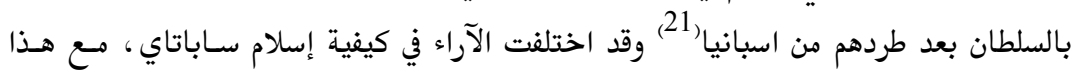

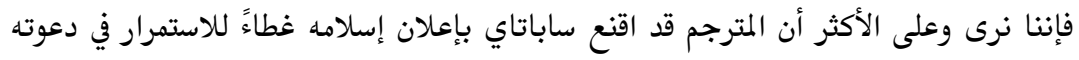
كمسيح منتظر وان المحكمة لم تشعر بذلك.

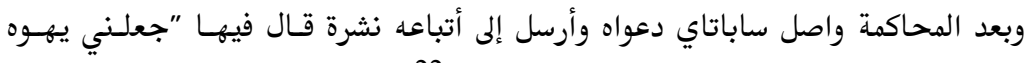

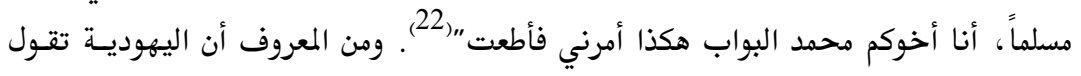
أن المسيح المنتظر سيبتلعه المسلمون، وقدم اخو ساباتاي التوضيح الآتي "كيان ساباتاي القديم المديم

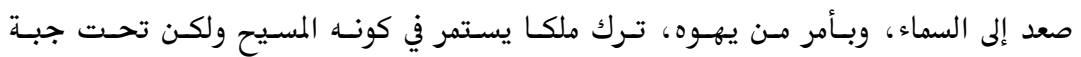

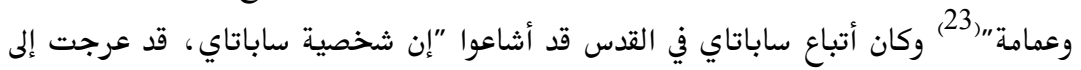
السماء، وحل محلها بأمر الله مسيح يرتدي ثوب مسلم" (24).

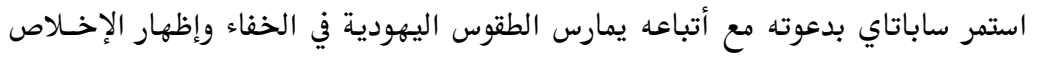

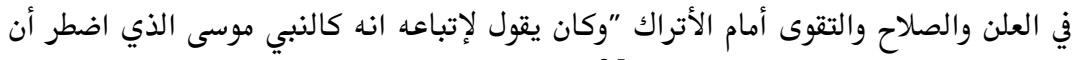
يبقى مدة من الزمن في قصور الفراعنة") وخلال استمراره بدعوته وعندما كان يعظ أتباعه باللغة العبريسة في (كنيسـت جشتهمة) في

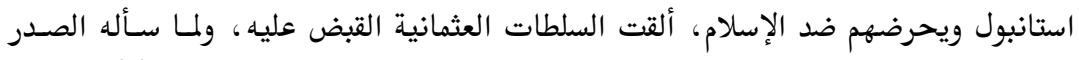

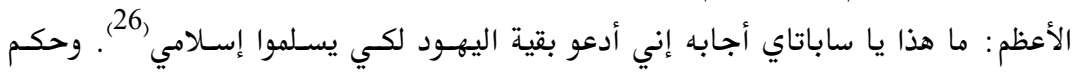

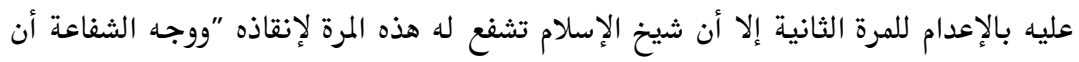

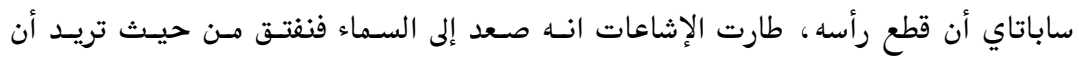

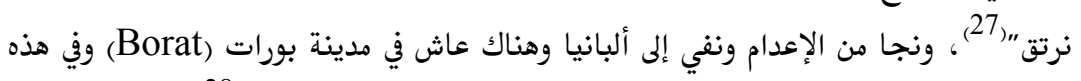

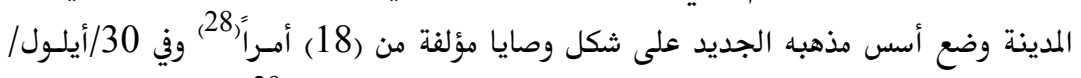

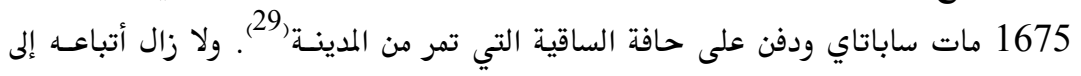

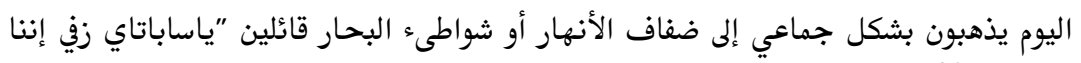
ننتظرك") (30) 
وقبل أن يموت ساباتاي جعل من مدينة سـلانيك مركـز اليهـود والمرتسدين (السبطائيون

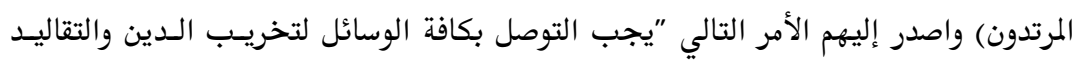

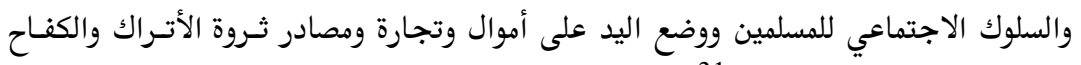
للسيطرة عليهم والتحكم بهم" (31). ثانياً: التسمية والخصوصية

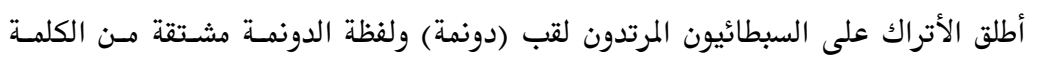

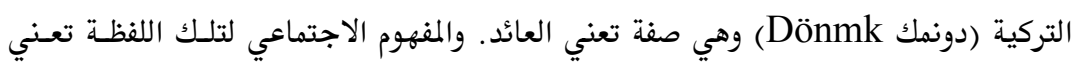

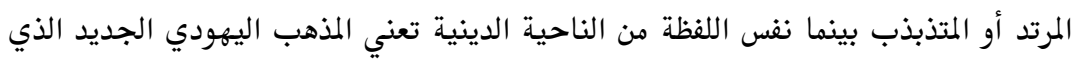

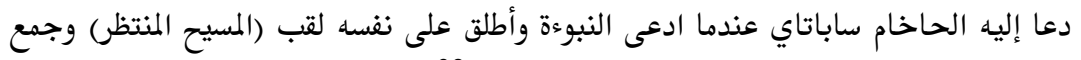

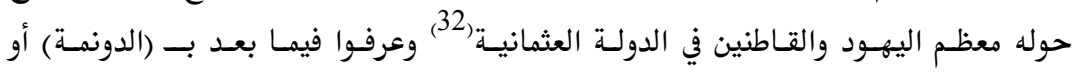
(السبطائيون). أما المفهوم السياسي لهذه اللفظة "يعني اليهود المسلمين الدذين لهـم كيـانهم

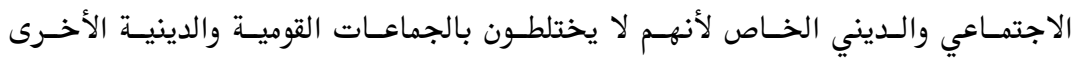

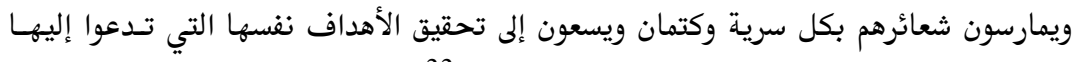

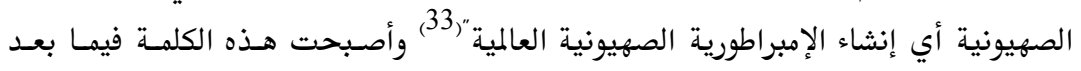

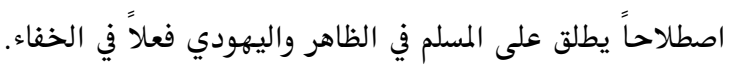

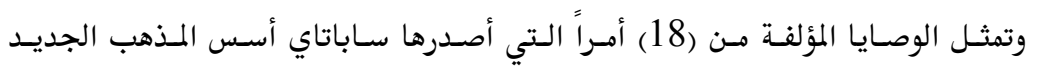

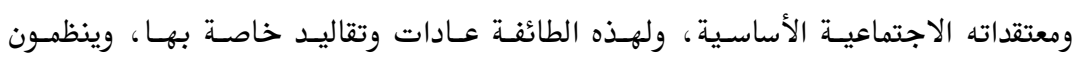

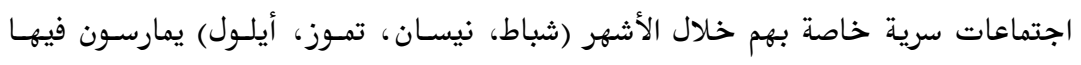

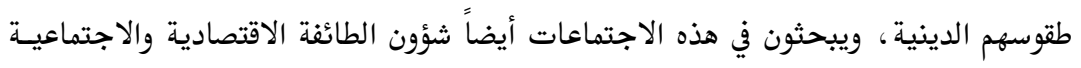

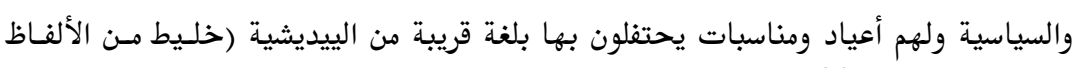

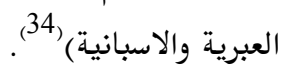
وفي مقابل ذلك في الظاهر يؤيدون الشعائر الدينية الإسلامية فيصـومون أحيانـاً ويحجـون الحئان أحياناً ويدخلون المساجد والجوامع للصلاة أحياناً 35. 
يهود الدونمة والانقلاب السياسي _. والدونمة ثلاث أقسام (فرق) رئيسية : اليعاقبة، القراقاشـية والقابانجيـة(36)، ويتكلمسون

لغتين الأولى تركية للتعامل مع الأتراك والثانية خليط مسن الاسـبانية والعبريسة للتعامـل فيمـا بينهم. ولكل واحد من أفراد الطائفة اسمان اسم يهودي خاص في الخفاء واسم إسلامي رسمي عام (37) - (37).

المبحث الثاني: الدونمة والانقلاب السياسي العثماني (1908) توسعت الدولـة العثمانيسة خاصـة نحسو الشـمال الغربسي الأوربسي وضسمت أقـوام واديـان مختلفة، وأصبحت في خطر السقوط حتى تولى السلطان محمود الثـاني الـذي وضـع الحجـر الأول للنظام الجديد. وخلفه السلطان عبدالحميد الذي صدر في زمانسه (فرمسان التسـويـة بسين أصناف الرعية) المعروف بـ "خط كلمانـه" عـام (1839) تم الخـط الهمـايوني عـام (1856) وبمقتضى هذين الخطين تم تامين الرعايا العثمانيين على أراضيهم وأموالهم وأعراضهم مهمـا كانت مذاهبههم، ومساواتهم أمام القانون. وعندما أفضت السـلطنة إلى السـلطان عبـد العزيـز تراجعت الدولة عن تنفيذ هذا القـانون(38) وبعد خلـع السـلطان عبـد العزيـز تـولى في 29 /

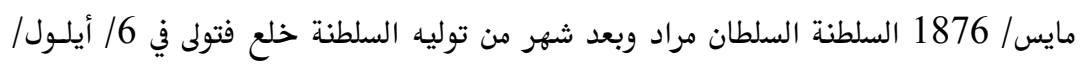
1876 السلطنة السلطان عبدالحميد الثاني، وكان قـد وعـد مسدحت باشـا قبـل ذلـك بمسنح القانون الأساسي (الدستور)، إلا انه في البدء تراجع السلطان عن وعـده، ونتيجـة العلاقـات

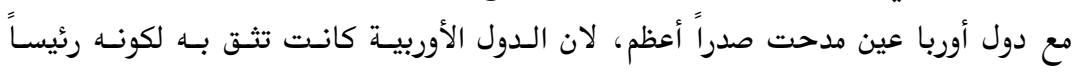
للأحرار وأوضع القانون الأساسي. وفي عام (1877) منحت الأمة العثمانية الدستور والحريسة لأول مرة، وفي شهر مـارس عـام (1877) اجتمـع مجلـس المبعوثـان الأول في سـراي (طولــة ياعجـة) وافتتح من قبل السلطان بإلقاء خطاب فيه، ولم يكد ينتظم المجلس وينظر في شؤون الدولة حتى حله السلطان في 14/ شباط/ 1878 عندما حضر المجلس رئيس الـوزراء وابلـغ فئ المجلس بان السلطان يأمر بحل مجلس المبعوثان إلى اجل غير معين(39).

اولاً: الانقلاب السياسي العثماني (1908) 
يذكر اورخان محمسد علي في كتابسه (السـلطان عبدالحميـد الثـاني) انسه في "21 مـايس 1889 اجتمع طالب الباني يدعى إبراهيم تيمور كـان يسدرس في المدرسـة الطبيـة العسكرية فئسية

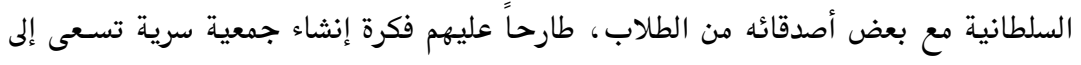

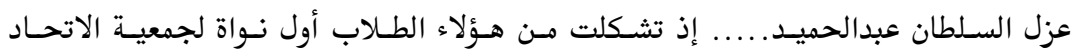

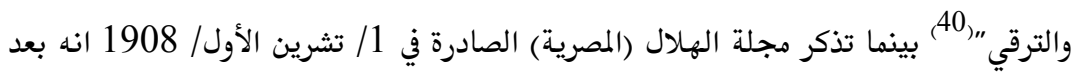

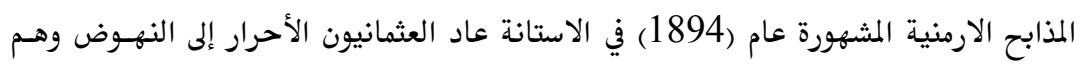

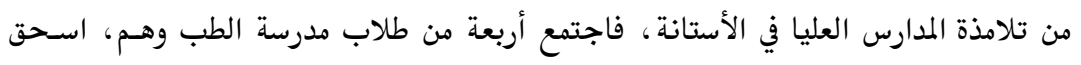

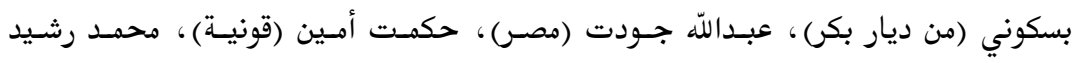

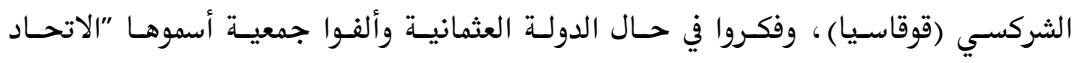

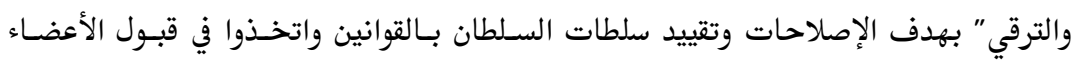
طرقاً تشبه طرق الماسونية مع إضافة أسلوب غريب للتكتم والسرية وكانت الجمعية العموميـة

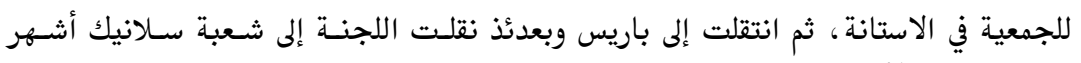

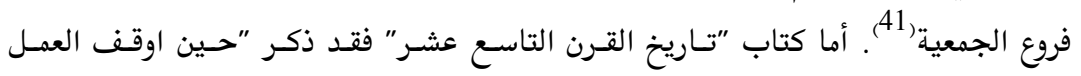

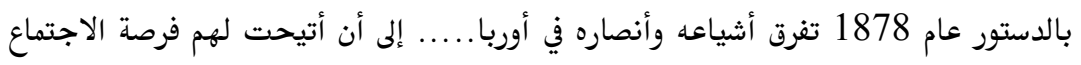

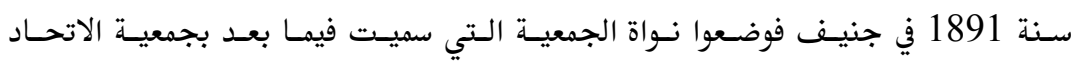
والترقي (42). مرت الجمعية بادوار نشطت فيها وضعفت سـواء في الـداخل أو الخـارج، حتى خــروج

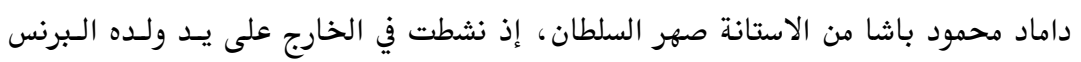

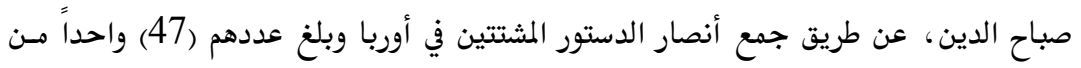

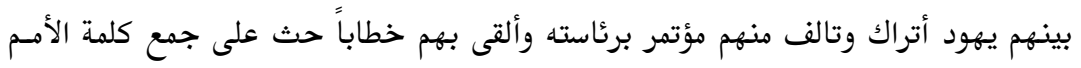

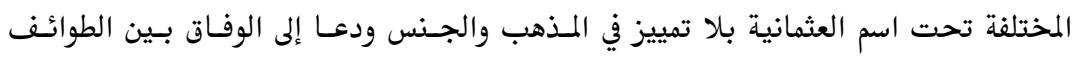

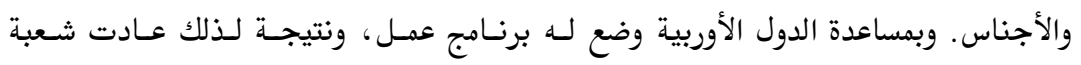

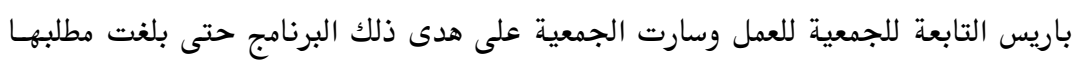
وهو الدستور(43). 


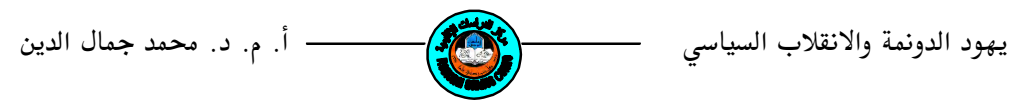

أما في داخل الدولة العثمانية فقد نشطت (شعبة مناستير) للجمعية في نشر مبادئهـا بـين

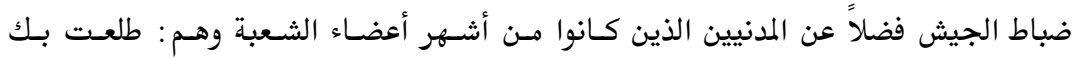

(سكرتير التلغرافات) ومدحت بك (رئيس حسابات المعارف) وحيدر بـك بـن مسدحت باشـا

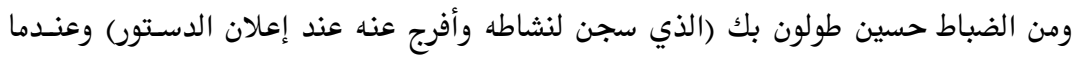

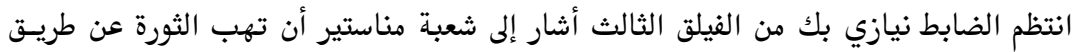
تشكيل العصابات الوطنية. وهو أول من ألف عصابته (عصابة نيازي) واقتدى به زميله التهاتي أنسور

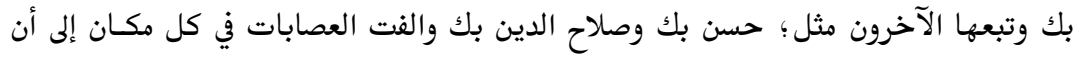

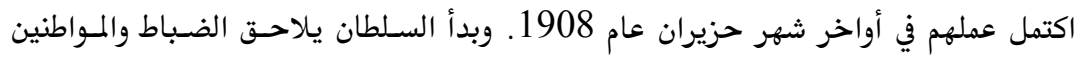
المنتمين للجمعية خاصة في سلانيك، وعلى هذا قررت إدارة الجمعية في سلانيك التي تتكسون من خمسة أعضاء، وذكرت في حينه مجلة الهلال الصادرة في شهر تشرين الأول عـام 1908

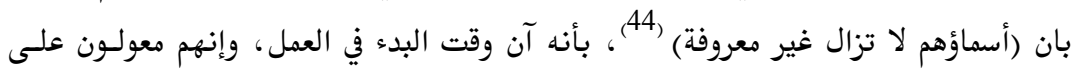

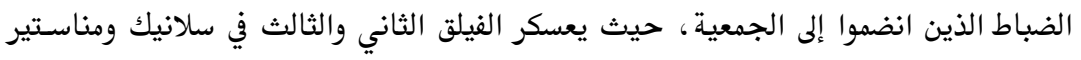

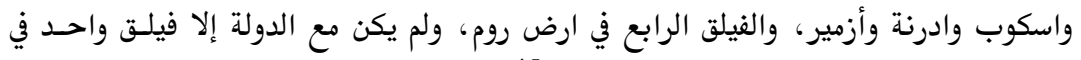
الأستانة وثلاث فيالق في بغداد ودمشق واليمن (45). وبدأت الجمعية في الأيام 21، 22، ونداد ودمثق واليمن 23، من شهر تموز عام 1908 ترسـل التلغرافـات إلى الصدر الأعظم من سلانيك ومناستير واسكوب وسرس وتضمنت هـذه التلغرافـات المطالبـة

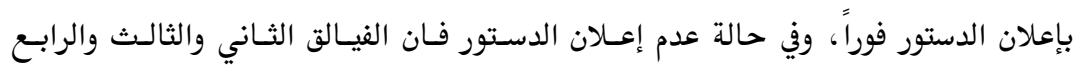

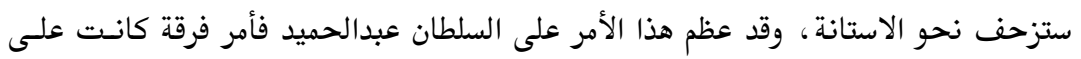

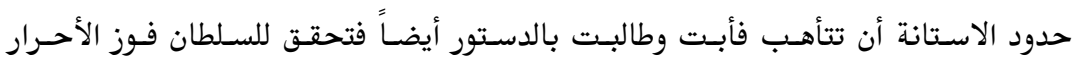

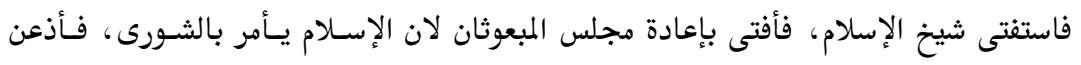

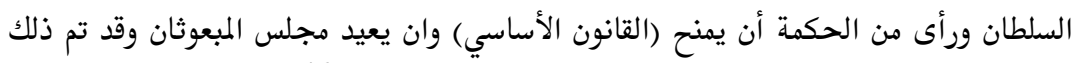

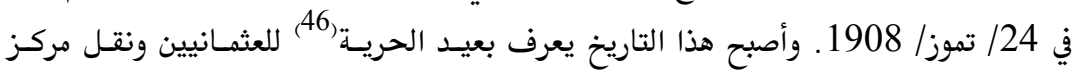
جمعية الاتحاد والترقي من سلانيك إلى الاستانة لاستلام السلطة تدريجياً. ثانياً: خلع السلطان عبدالحميد الثاني (1909) 
أنذ أن أعلن الدستور ازداد النفور بين أنصار السلطان وجماعة الاتحساد والترقي، وكسان

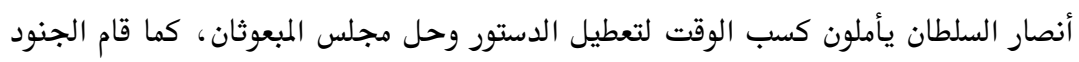

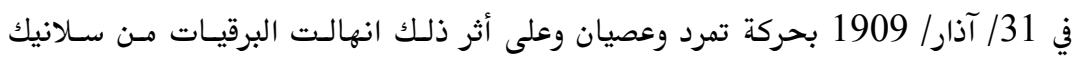

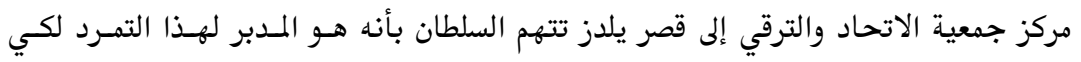

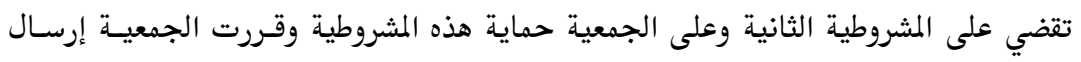

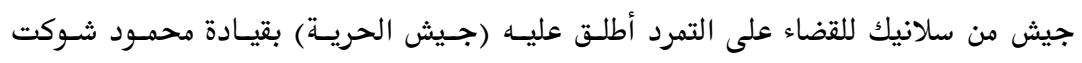

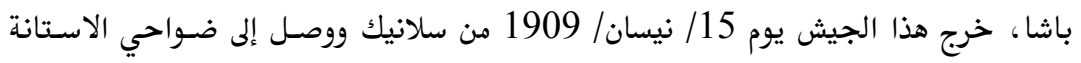

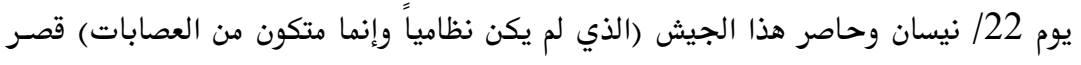

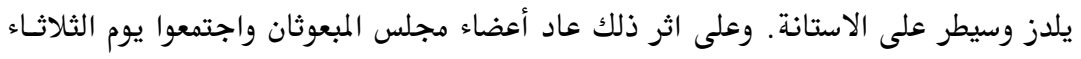

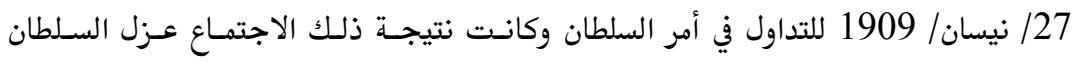

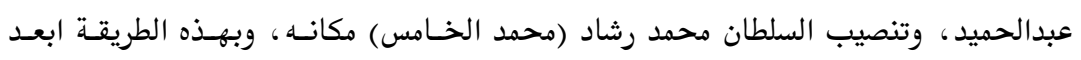

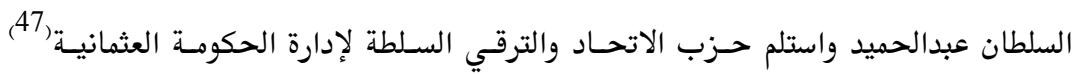

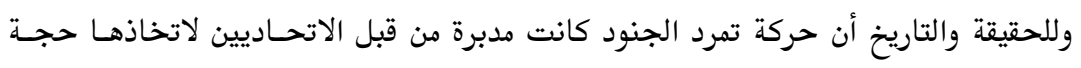

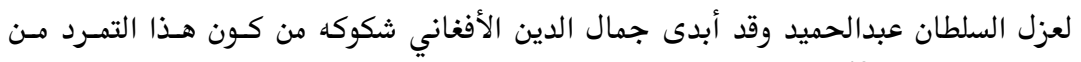
تدبير الاتحاديين(48). وفي نغس اليوم 27/ نيسان / 1909 حضر وفد إلى قصر يلسدز مكلف مسن قبـل مجلس الدي

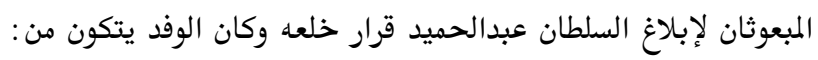
1 ! الفريق عارف حكمت باشا (عضو مجلس الأعيان وياور السلطان السابق). 2 إرام أفندي (ارمني عضو في مجلس المبعوثان).

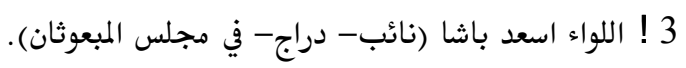

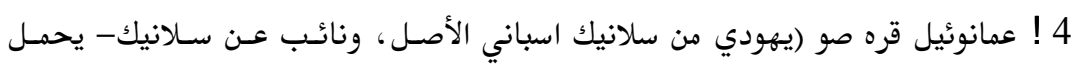

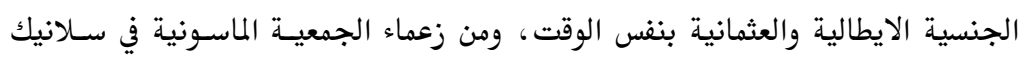

$$
\text { والمحفل الماسوني الايطالي) (49). }
$$


يهود الدونمة والانقلاب السياسي وبعد تبليغ السلطان عبدالحميد بقرار خلعه التفت إلى الوفد مشيراً إلى (قره صو)، قـائلاً

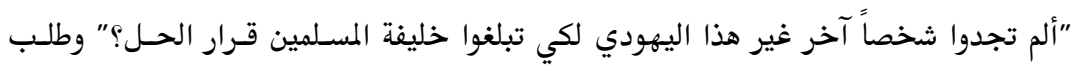

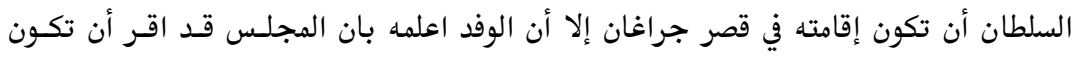

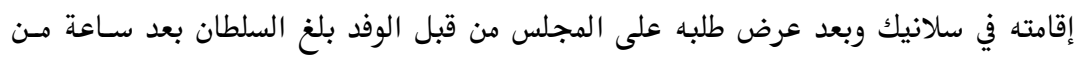
مغادرة الوفد القصر للتهيؤ فوراً للسفر إلى سلانيك (50).

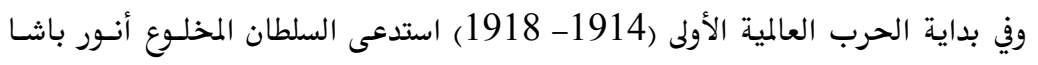

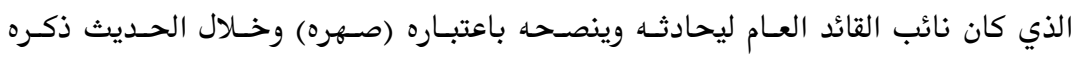

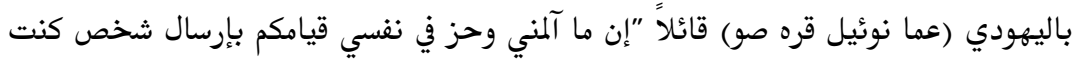

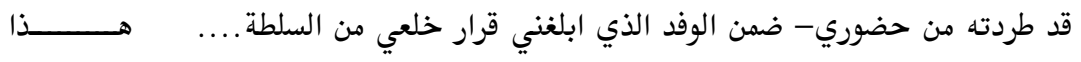

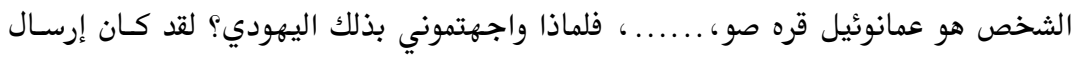

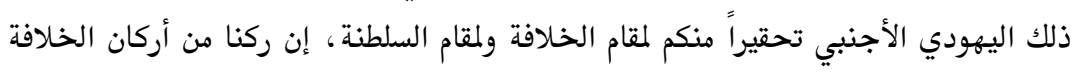

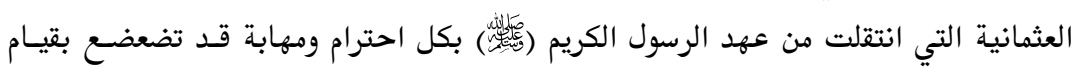

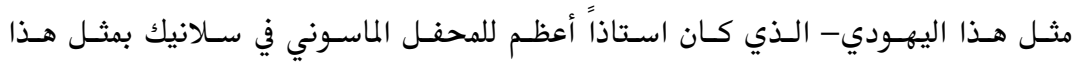
التبليغ "(51). وليس لنا إلا أن نقر بكلام السلطان عبدالحميد ، بأن هذا موقف من المواقف التي شهدها

التاريخ تجاه الإسلام والمسلمين ولم يزل يتحين الفرص لتكرارها.

ثالثاً: دور يهود الدونمة أفضل ما يوضح دور يهود الدونمة من الانقلاب السياسي العثماني (1908) وما أعقبـه،

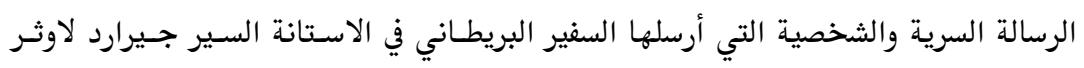

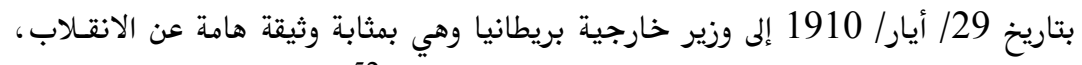
وسنذكر أهم النصوص التي تضمنتها وتتعلق بموضوع البحث (52). ! "ان حركة تركيا الفتاة في باريس كانست مستقلة عسن حركسة تركيـا الفتـاة في سـالونيكا: وكانت تجهل معظم تنظيماتها وإجراءاتها الداخلية" 


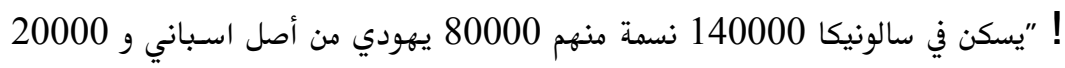
من طائفة سبط لاوي ندا، ومن اليهود المتظاهرين بالإسلام (دونمة)".

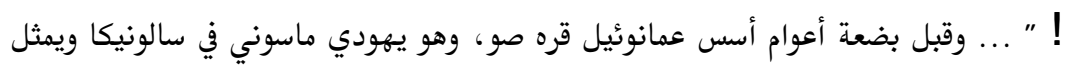
الآن مدينة سالونيكا في مجلس المبعوثان العثماني بالتعاون مع الماسونية الايطاليسة محفـلاً

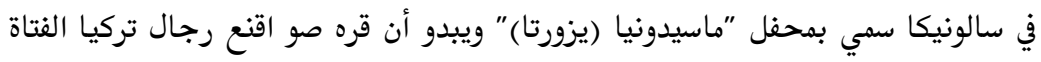

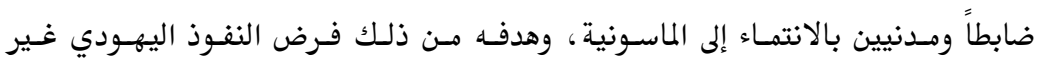
المستساغ على الأوضاع الجديدة في تركيا". ! "ويظهر أن المخططين لحركة تركيا الفتاة في سالونيكا كانوا بالدرجة الأولى من اليهود".

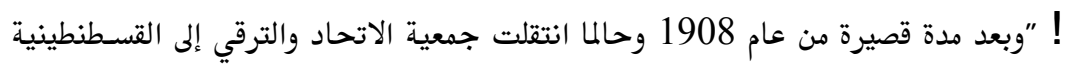

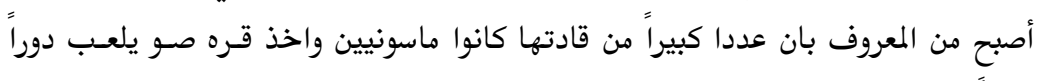

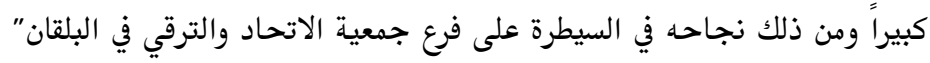

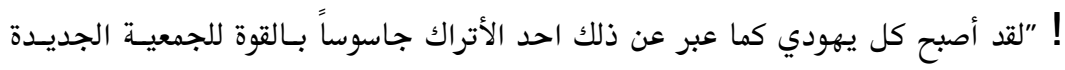
وبدأ الناس يقولون أن الحركة إنما هي حركة يهودية أكثر مما هي دي تركية ".

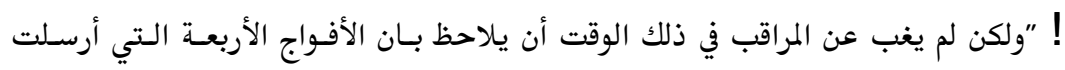

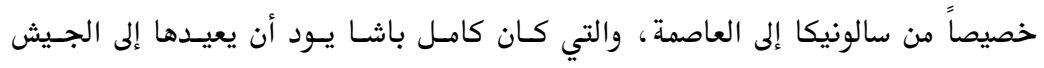

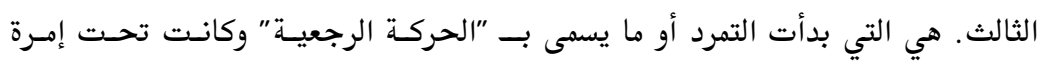

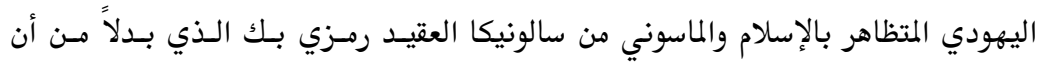
يحاكم أمام المحكمة العرفية بسبب تصرف العساكر الذين كانوا تحت إمرته عين رئيساً لأركان حرب السلطان محمد الخامس".

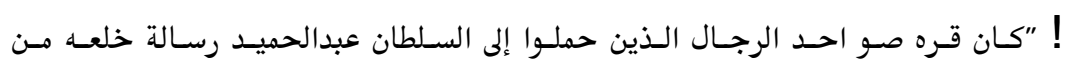
السلطنة". ! "نقل عبدالحميد إلى سالونيكا، وحسبس عنـد صسيرفي جمعيـة الاتحساد والترقي اليهـودي الايطالي ، في حين عين أخ لرمزي بك مشرفا عليه". 
يهود الدونمة والانقلاب السياسي

! "بعد أن تم خلع السلطان عبدالحميد أخذت الجرائد اليهودية في سالونيكا تزف البشـائر

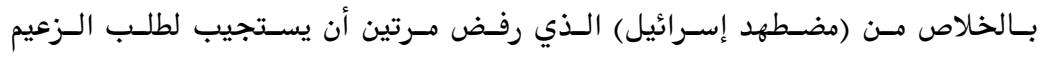

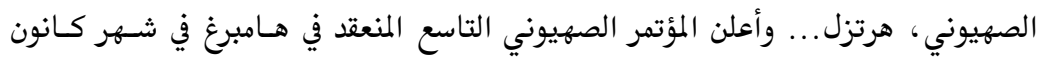

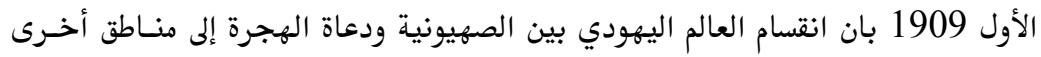

غير فلسطين قد انتهى. وعاد اليهود موحدين بفضل (معجزة الثورة التركية)".

! ".... شبكة المحافل الماسونية في سالونيكا ومقدونيا كان يقودها، أو يخطط لها لهان اليهود".

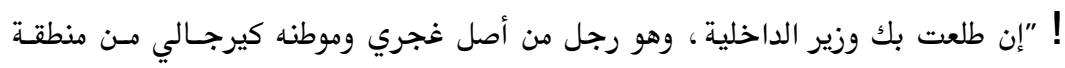

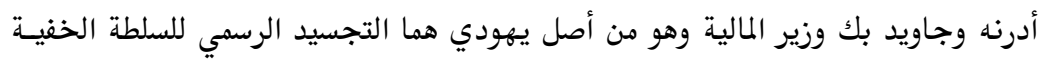

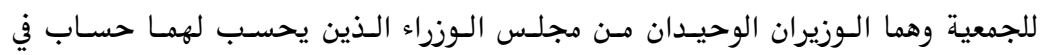

الحقيقة، وهما يمثلان أيضاً قمة الماسونية في تركيا".

! ! "ان معظم قادة الجمعية هم صراحة علمانيون وعقلانيون".

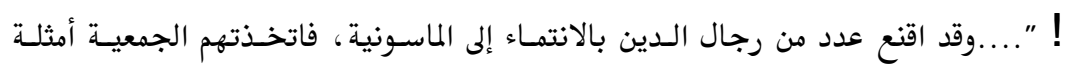

للتغلب على شكوك الشعب بالماسونية وكراهيته لها. وقد وصف احد الأتراك هذه الطريقة

$$
\text { بأنها عملية تحذير الشعب بحشيشة يهودية" الشعب بالمونية وكراهيت }
$$

! "ان هذه الحركة هي في جوهرها وأساسها حركة يهودية تركية".

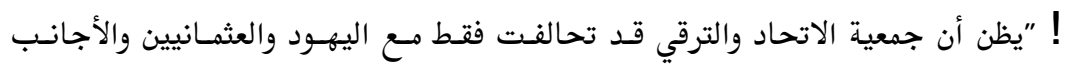

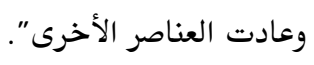

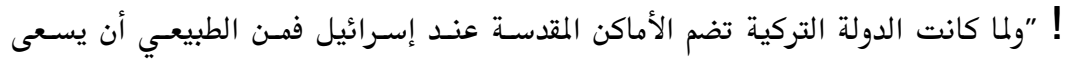

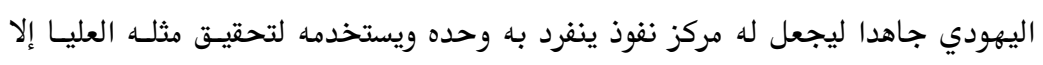

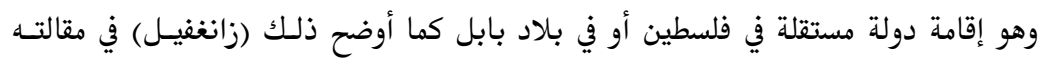

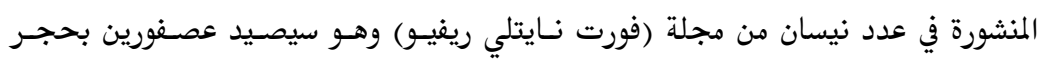

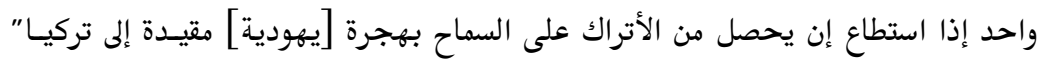

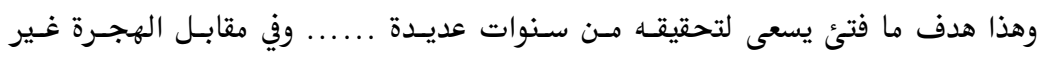

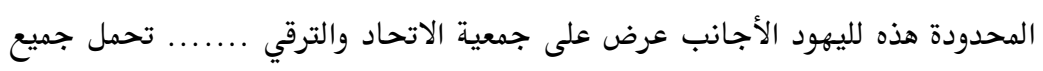


! "..... إن فلسطين والعراق هما هدف اليهود النهائي والبعيد وأما الهدف المباشر القريسب الذي يسعى اليهود إلى تحقيقه فهو السيطرة الاقتصادية التامة على تركيا وإقامة المشاريع

الجديدة فيها".

من هذه النصوص الواردة في رسـالة السفير البريطساني يتسبين لنـا بـان جمعيـة الاتحساد

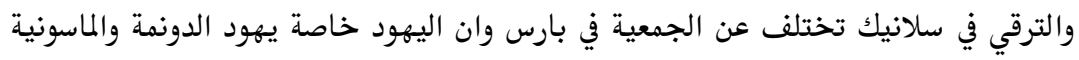

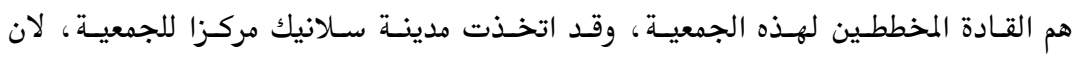

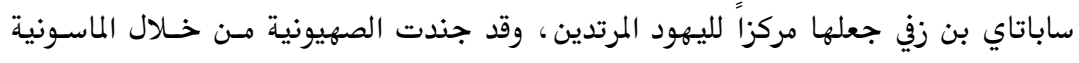

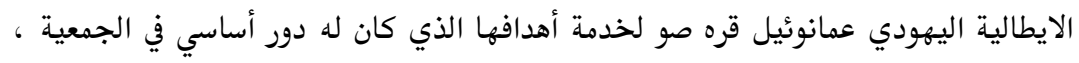

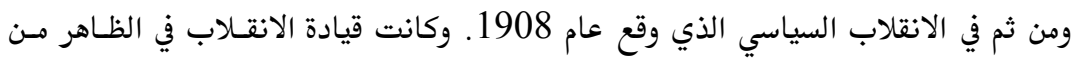

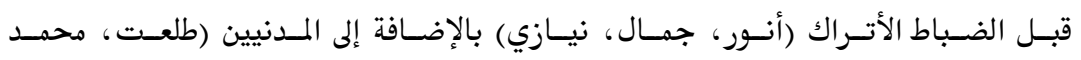

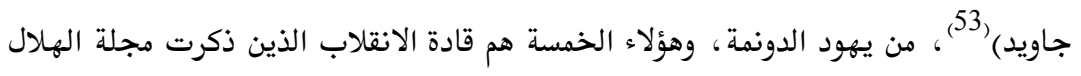

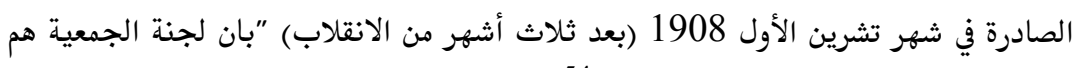

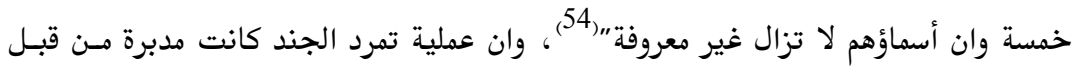

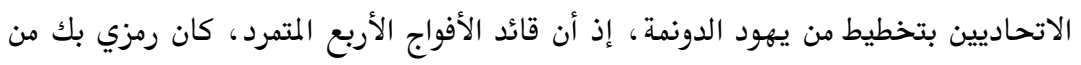

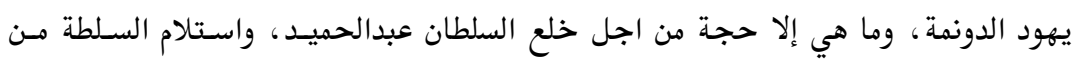

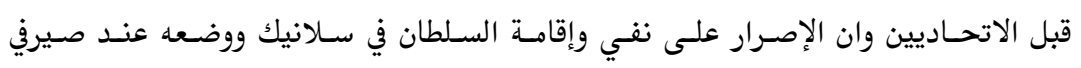

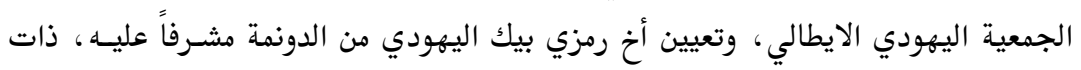

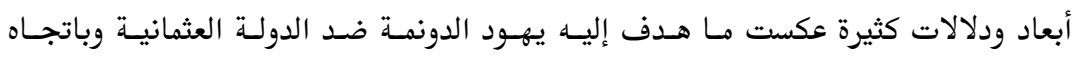

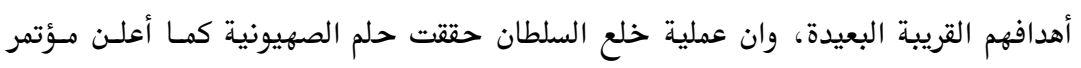

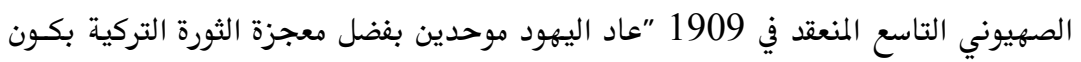

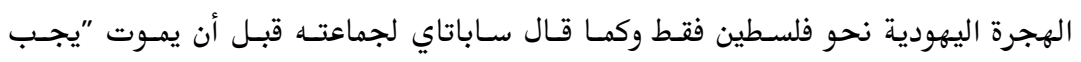
التوصل بكل الوسائل لتخريب الدين والتقاليد والسلوك الاجتماعي"، فقد ولئ اتجـهـ الاتحساديون

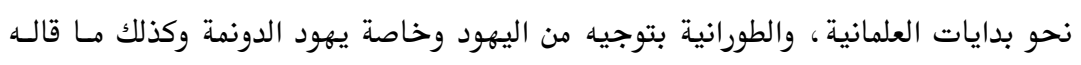

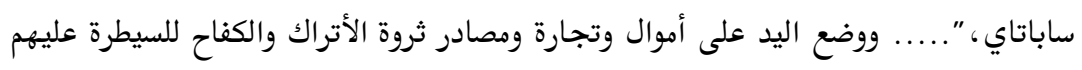


يهود الدونمة والانقلاب السياسي

والتحكم بهم" فقد تحقق لهم السيطرة الاقتصادية التامة وإقامة المشاريع الجديدة والنفوذ إلى

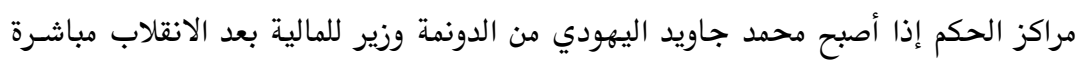

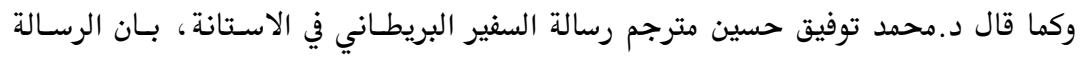

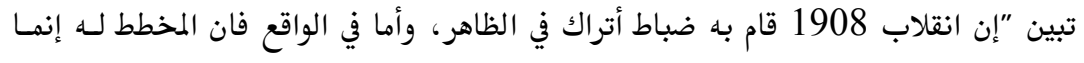

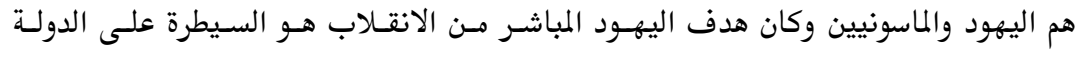

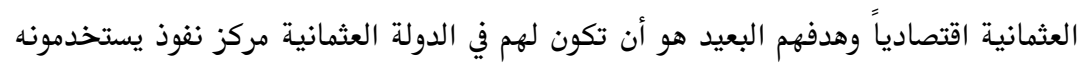

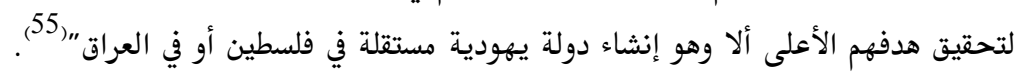
رابعاً: الدونمة والهجرة اليهودية إلى فلسطين

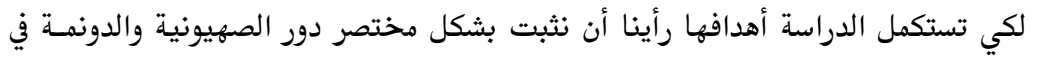
عملية الهجرة اليهودية إلى فلسطين أواخر أيام الدولة العثمانية.

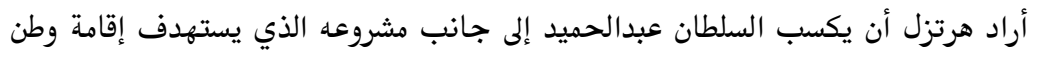
قومي لليهود في فلسطين وقال هرتزل "..... اعـترف بـان القـرار في يـدي صـاحب الجدي الجلالـة

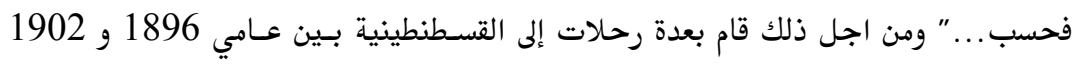
واستدعي إلى الباب العالي وشرع بالتفاوض بين (قوة وقوة) على حد تعبيره، وخرج بنتيجـة أن السلطان يقف بعنف ضد مشروع إقامة "دولة يهودية" في فلسطين ويمنع الهجرة اليهودية إليها والاستيطان فيها.56. وقد تبنى السلطان أربع إجراءات تجاه الصهيونية هي: -

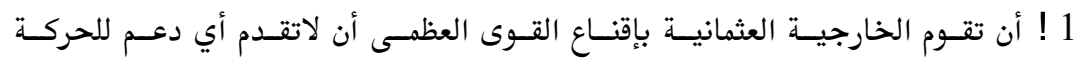
الصهيونية. 2 ! 2 على وزارة الداخلية اتخاذ الإجراءات لمنع دخول الصهاينة إلى البلاد.

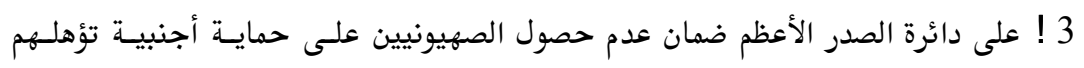
للحصول على حقوق الامتيازات الخاصة.

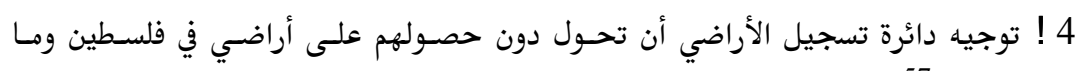

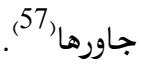


وقد نشـط الدبلوماسيون العثمـانيون في متابعـة حركسة الصهيونية فـالوزير العثمـاني في

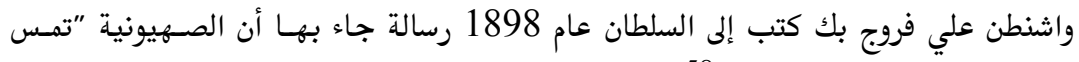

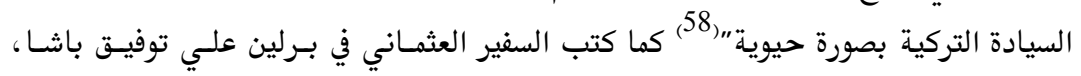

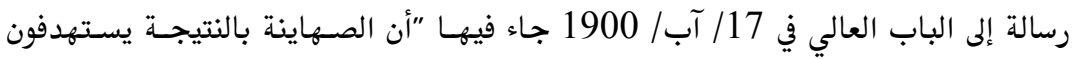

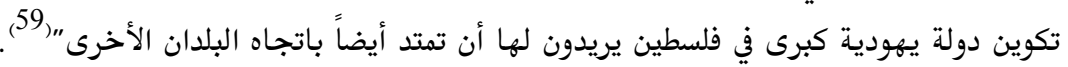

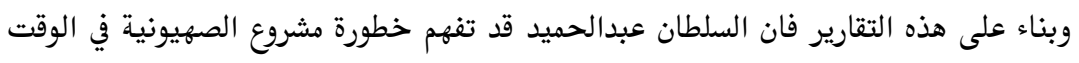

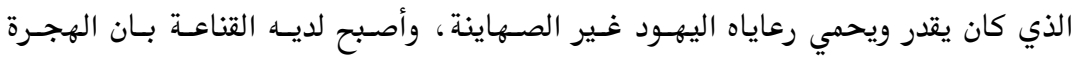

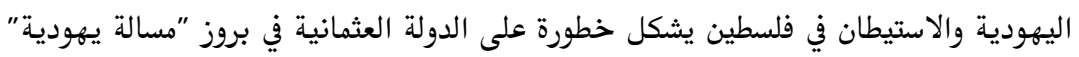

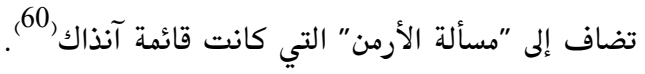

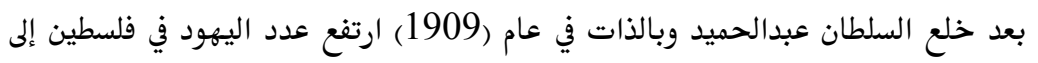

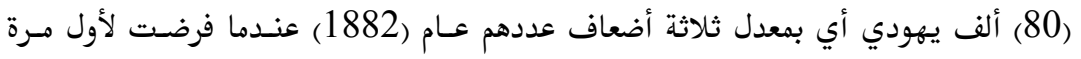

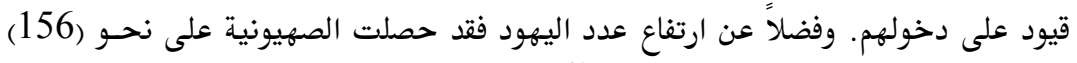

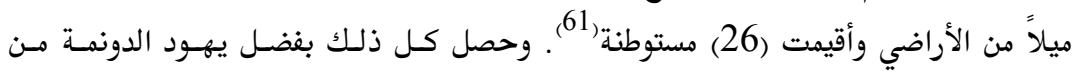

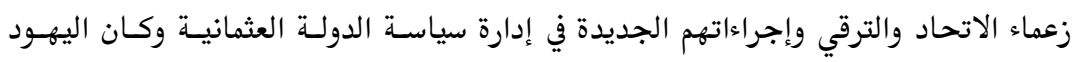

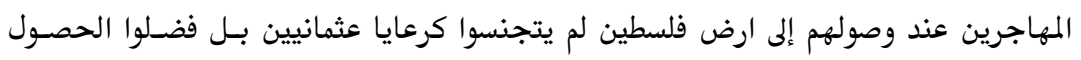

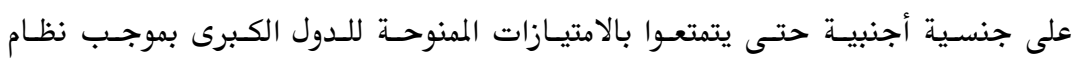

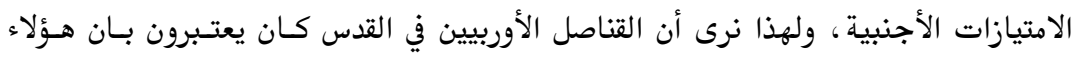

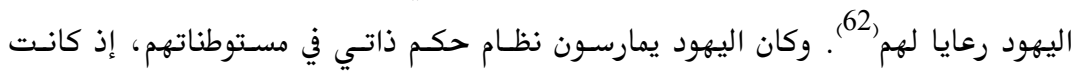

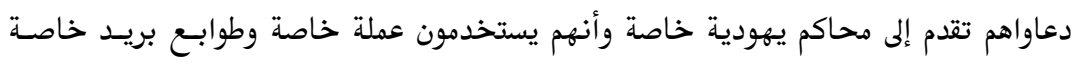

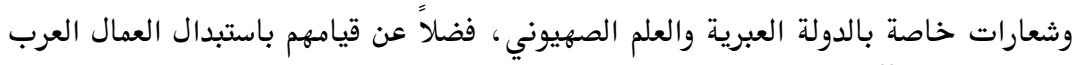

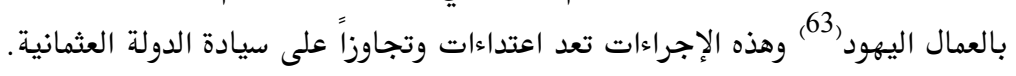

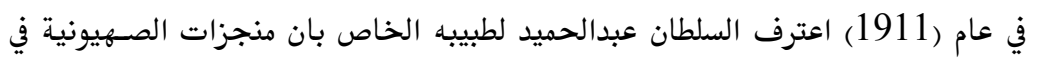

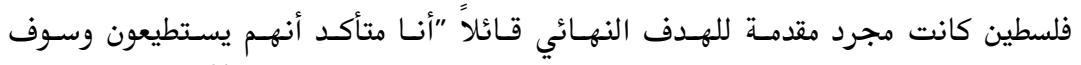

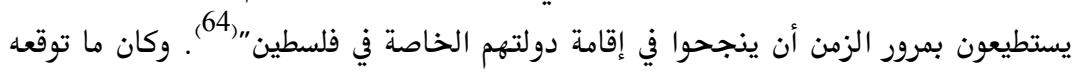




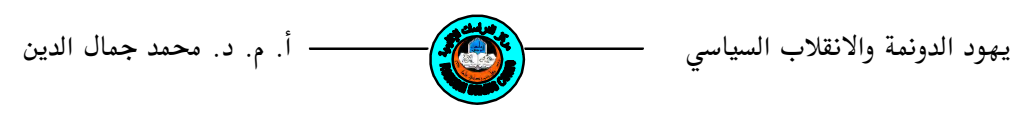

حقيقة واقعية على الرغم من معارضته للصهيونية وان ما رسمته الصهيونية كما جاء في بداية

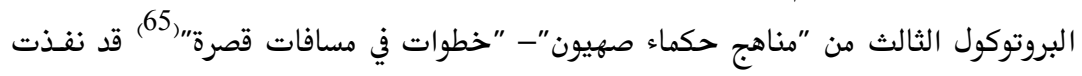

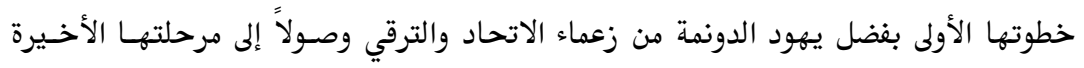
عند إقامة الدولة العبرية عام 1948.

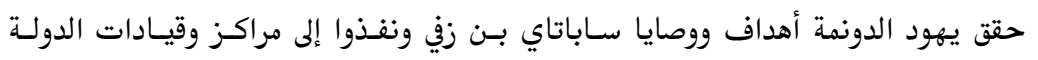

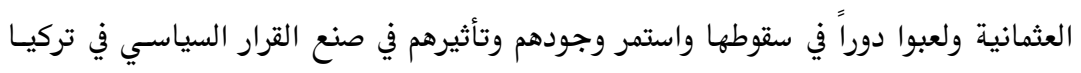
الحديثة باتجاه التعاطف وإسناد الصهيونية و(إسرائيل).

لعبت طائفة الدونمة دوراً واضحاً في الانتـلاب السياسي العثمـاني (1908)، وفي عمليـة

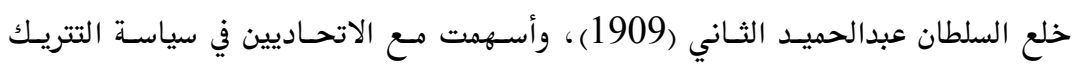

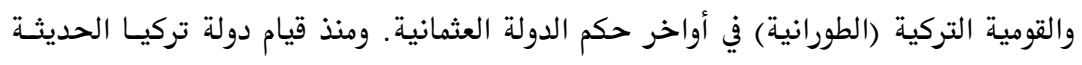

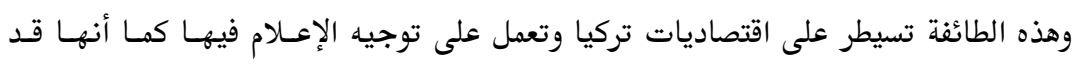

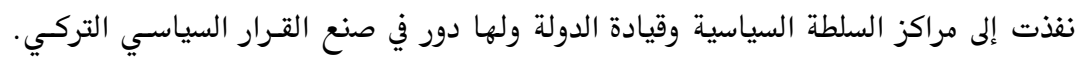

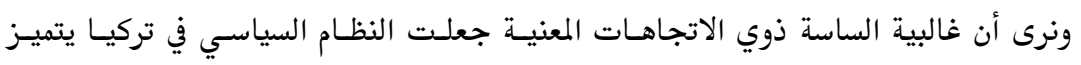

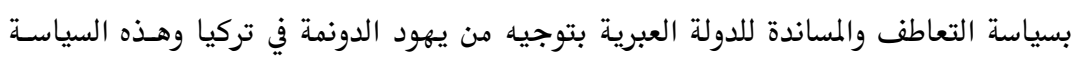

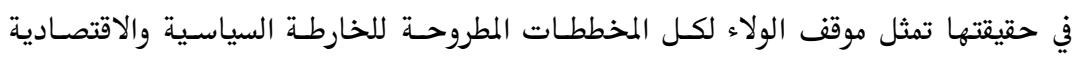
للمنطقة وفقاً للمتغيرات الإقليمية والدولية. 


$$
\text { دراسات إقليمية } 7 \text { (21) }
$$

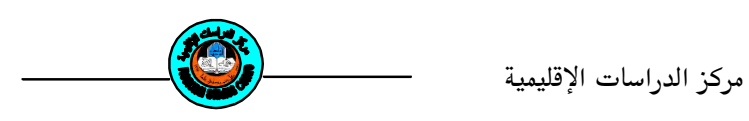

$$
\text { باعتناق الأقوام الأخرى للإسلام من اجلناق اليهود للإسلام في تركيا والتظاهر به مع الاحتفـاظ بـديانتهم شـبيه }
$$

\title{
Donmk Jews And Ottoman Coup-d' etat (1908)
}

\author{
Dr. Mohanmed Jamal Aldin Alalawi \\ College of Political Scienes-Mosul University \\ Alstract
}

\begin{abstract}
In the second half of the $17^{\text {th }}$ century, the Ottoman state encountered historic and political circumstances which led to the rise of "Dönmk Jews" sect through the rabbi Sabbatai Sebi from Azmir when the latter declared himself an Expected Messiah.

This sect is a Jewish one pretending to be Muslim, while it secretly exercises special religious rites. This sect is called the "Sabbai Sect". It had an impact on the Ottoman internal affairs in the
\end{abstract}




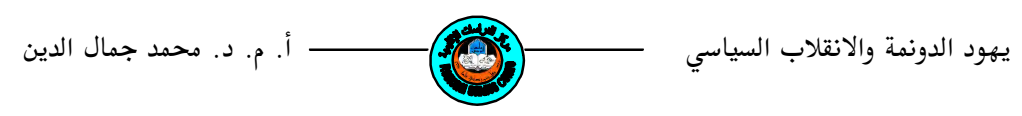

period of sultan Abdulhameed II, and that was evident through its role in the Ottoman coup in 1908 and the overthrowing of the sultan in 1909. It also affected the policy adopted by the assembly of AlItihad Wal Taraqqi while holding power and managing the Ottoman state affairs. Embracing Islam by the Jews in Turkey and pretending with that, keeping their religion, is similar to doing that by other people for the purpose of achieving the goals of their original doctrines.

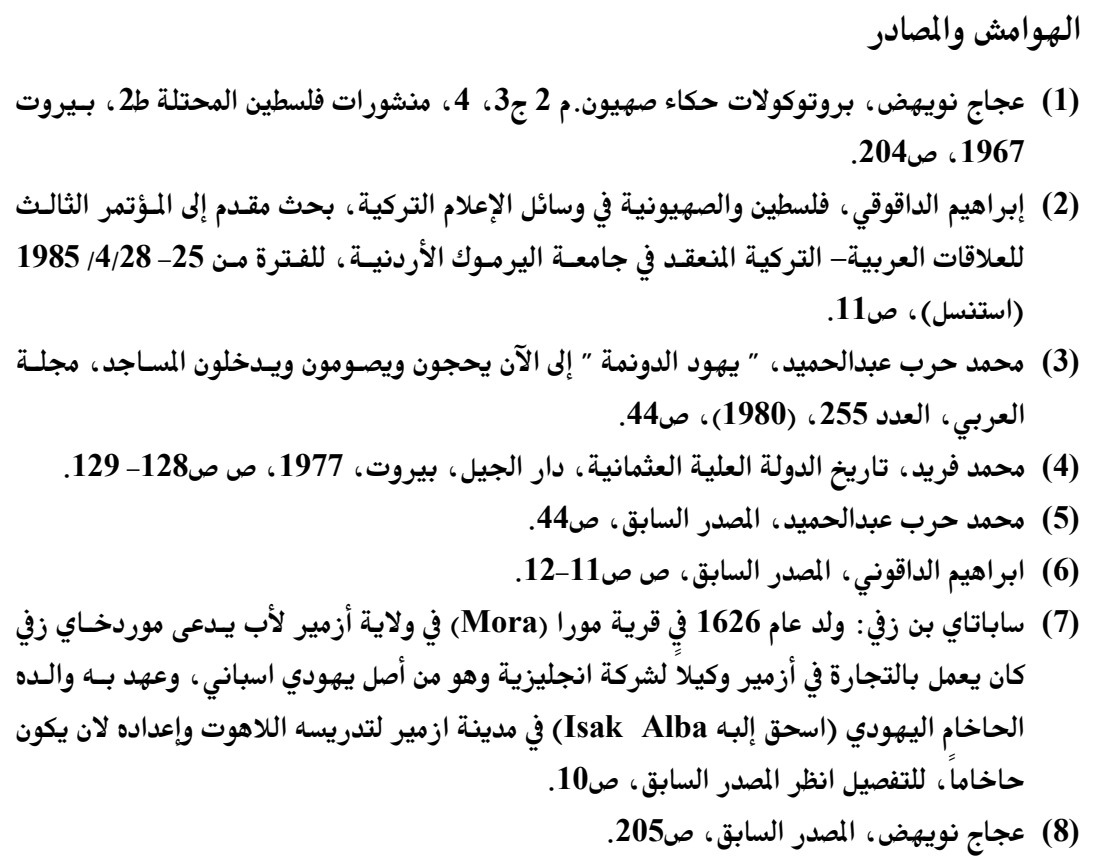




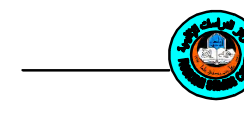

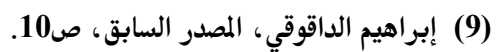

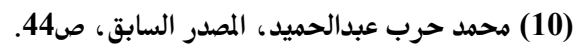

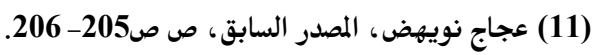

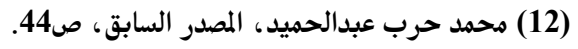

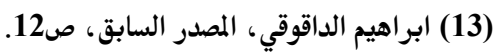

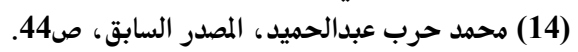

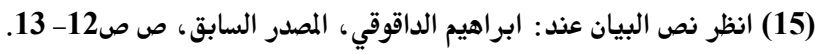

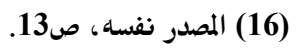

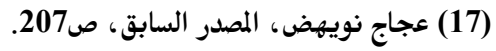

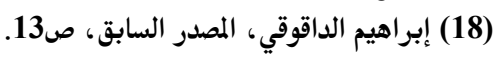

(19) الفيلسوف اليهودي سيمينوزا (1632- 1677) وكان من معاصري ساباتاي، انظر عجاج نويهض،

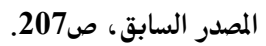

(20) إبراهيم الداقوقي، المصدر السابق، ص13.

(21) عن الآراء المتباينة في المحاكمة انظر كل من:

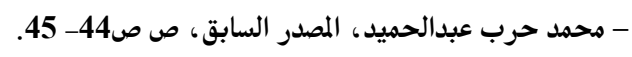

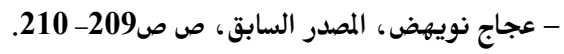

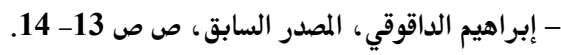

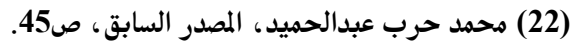

(23) (المصدر نفسه.

(24) عجاج نويهض، المصدر السابق، ص210.

(25) د. احمد نوري النعيمي، اثر الأقلية اليهودية في سياسة الدولة العثمانية تجاه فلسطين، بغداد الداد،

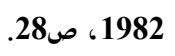

(26) عجاج نويهض، المصدر السابق، ص211.

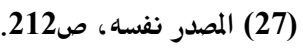

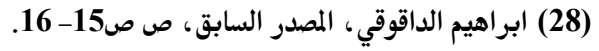

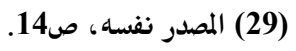

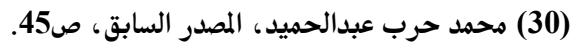

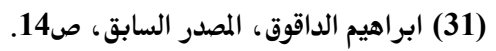




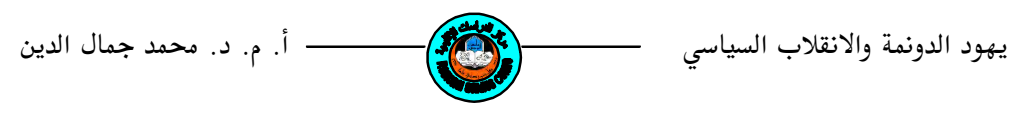

(32) المصدر نفسه، ص877، ومصطفى طوران (يهود الدونمة)، ترجمة كمال خوجه ، دار السلام ، ط1970،

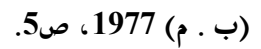

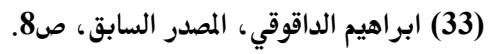

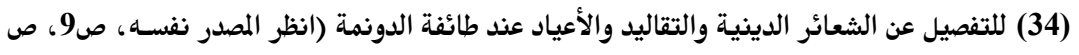

ص ص14-18).

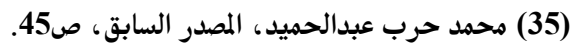

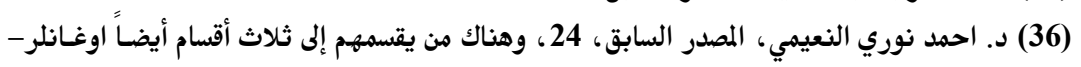

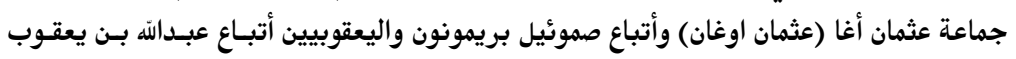

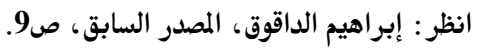

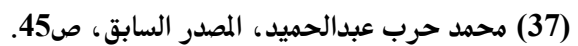

(38) الانقلاب السياسي العثماني، مجلة الهلال (الجزء الأول من السنة السـابعة عشرة) 10 10/ تشرين

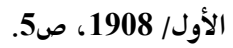

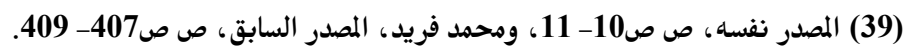

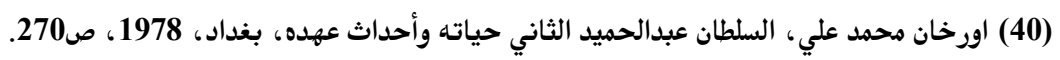

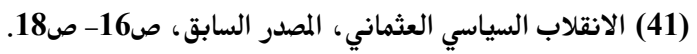

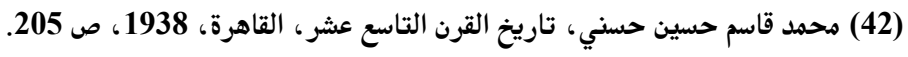

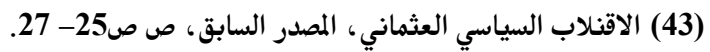

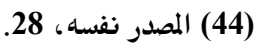

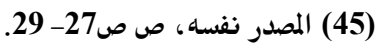

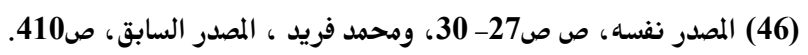

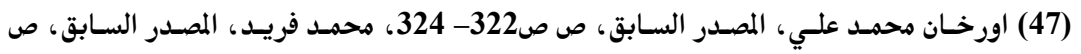

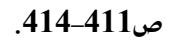

(48) (اورخان محمد علي، المصدر السابق، ص327.

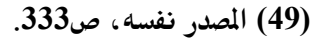

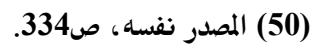

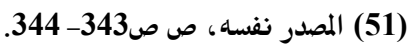

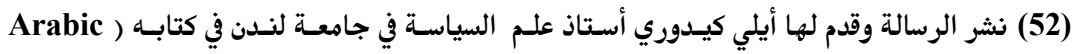

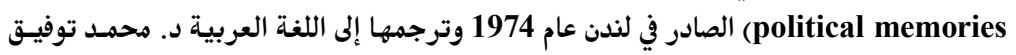

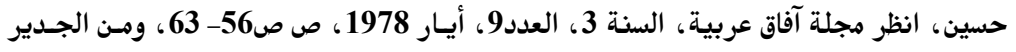

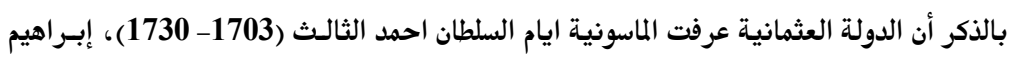

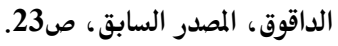




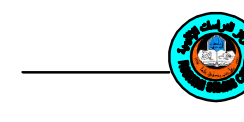

(53) قادة الانقلاب السياسي العثماني 1908، وهم خمسة:

- طلعت باشا: (1872- 1921) أصبح وزير الداخلية بعد الانقلاب، ثـم تصدر السوزارة (1912-

1918)

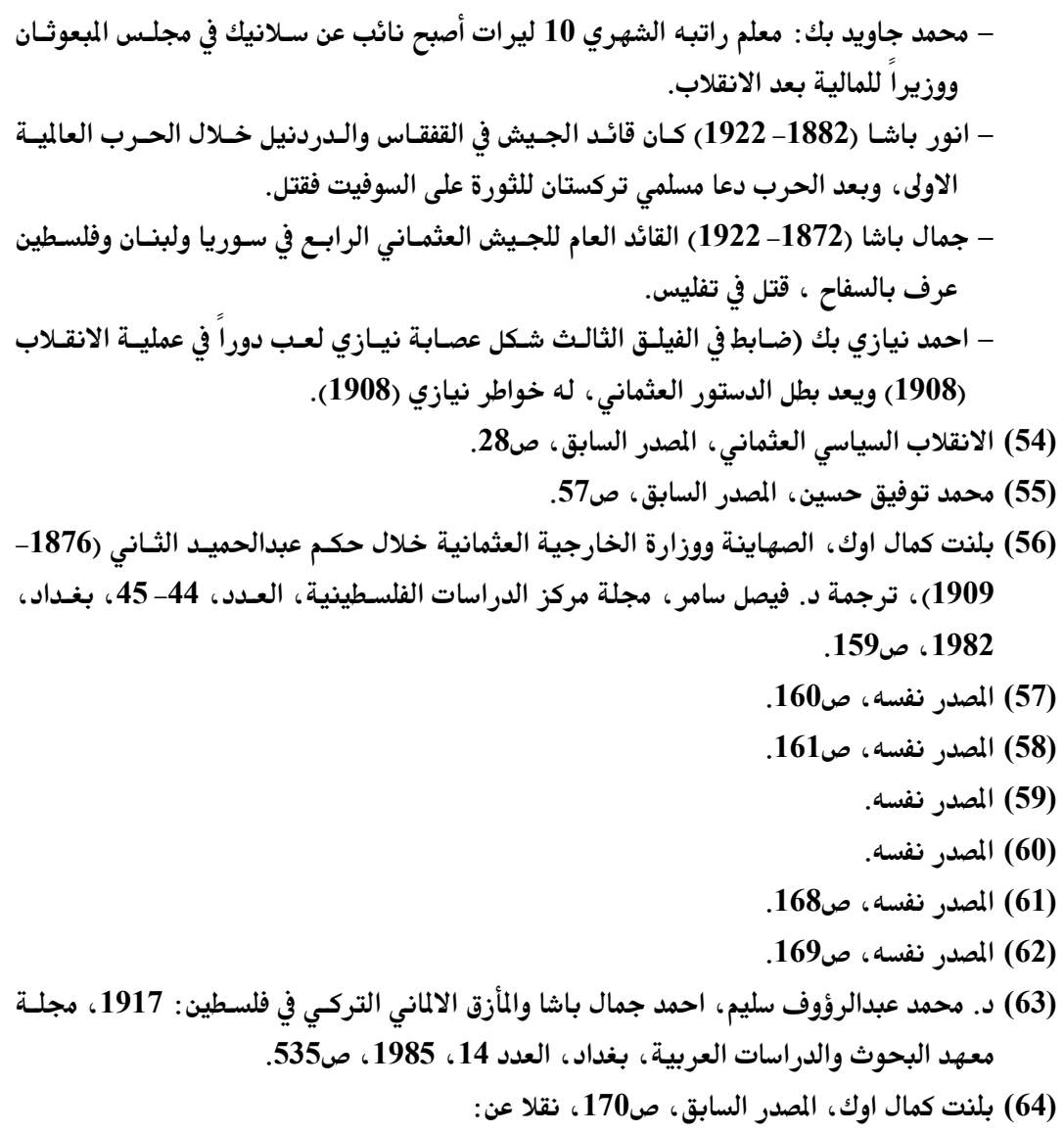

Arib Huscyin bey, Hatiralar, Turkish historical association y-255,p.18.

(65) عجاج نويهض، المصدر السابق، ص92. 